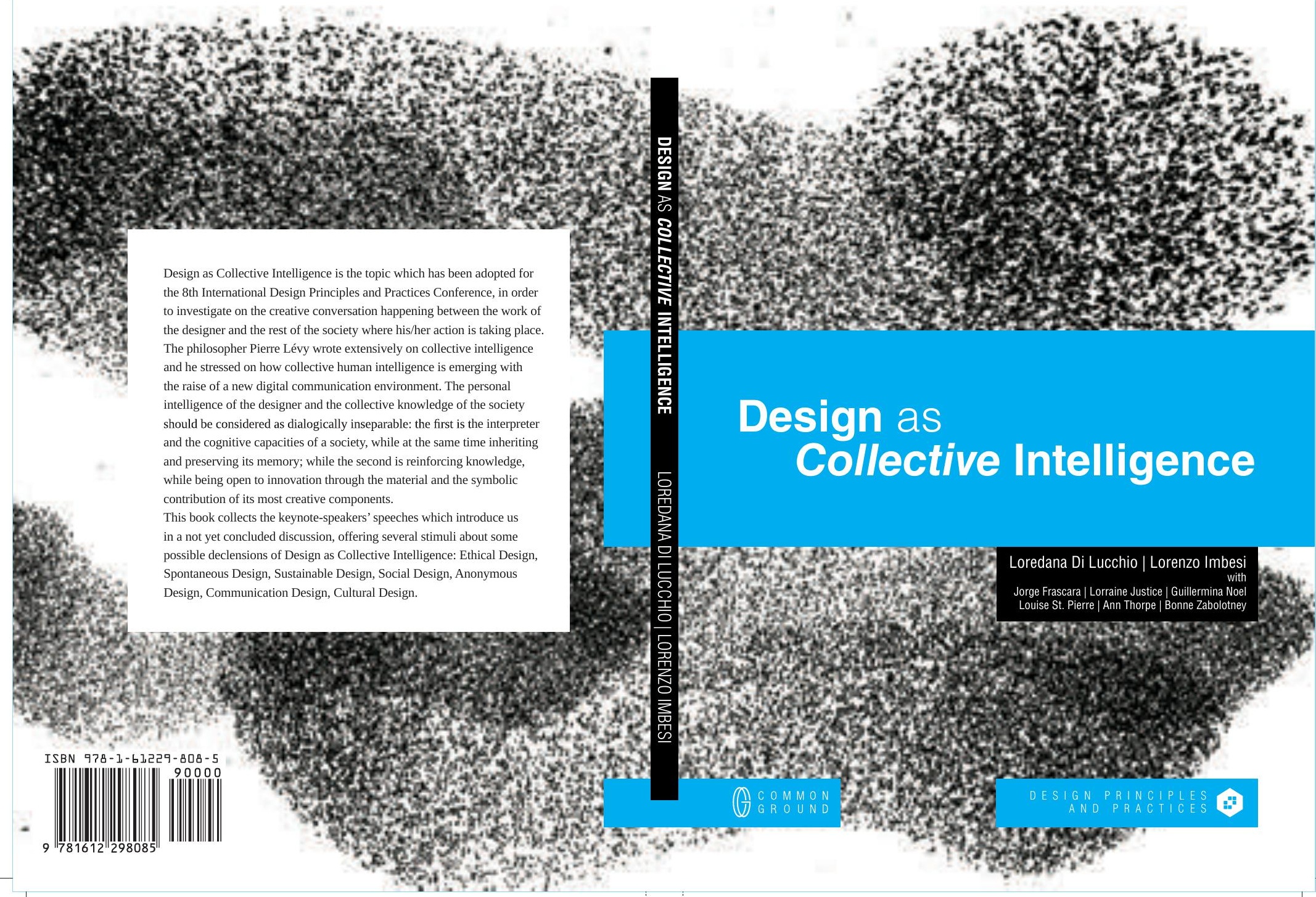




\section{Design as Collective Intelligence}

Loredana Di Lucchio | Lorenzo Imbesi

Jorge Frascara | Lorraine Justice | Guillermina Noel

First published in 2017 in Champaign, Illinois, USA

by Common Ground Research Networks

Louise St. Pierre | Ann Thorpe | Bonne Zabolotney

as part of the On Design book imprint
Book imprint editors: Loredana Di Lucchio and Lorenzo Imbesi

Copyright $\odot$ Loredana Di Lucchio, Lorenzo Imbesi and the chapter authors, 2017

All rights reserved. Apart from fair dealing for the purposes of study, research, criticism or review as

permitted under the applicable copyright legislation, no part of this book may be reproduced by any process without written permission from the publisher.

Library of Congress Cataloging-in-Publication Data

Design as collective intelligence / Edited by Loredana Di Lucchio, Lorenzo Imbesi. pages $\mathrm{cm} 14.8$ × 21.0

Includes bibliographical references.

ISBN 978-1-61229-808-5 (pbk : alk. paper) ISBN 978-1-61229-809-2 (pdf)

1. Design--Congresses. 2. Design services--Congresses. 3. Group decision making--Congresses. 4. Social choice--Congresses. I. Di Lucchio, Loredana, editor. II. Imbesi, Lorenzo, editor. III. Title.

\#\#\#\#.\#\#\#\#\#\#

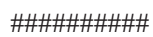




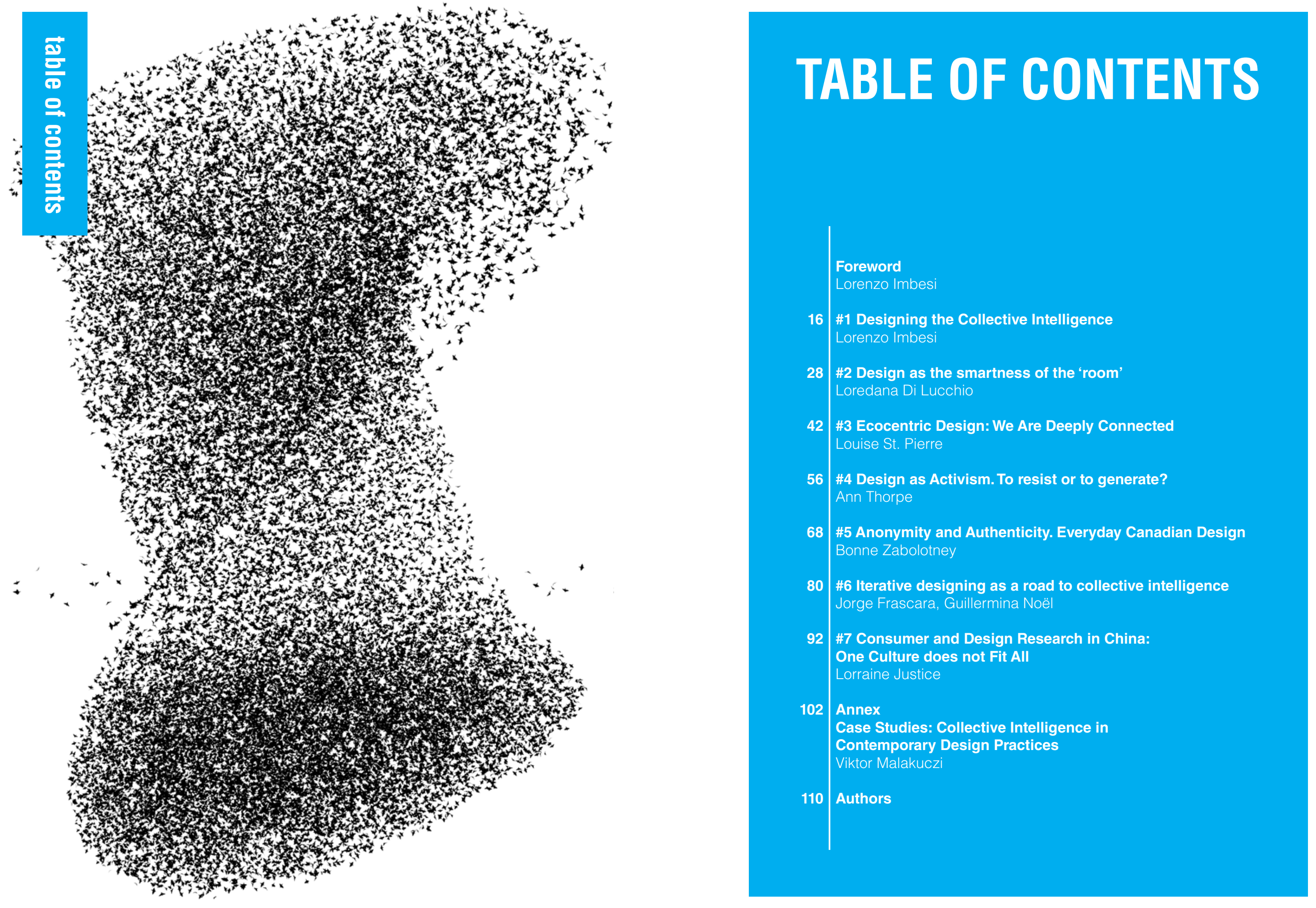




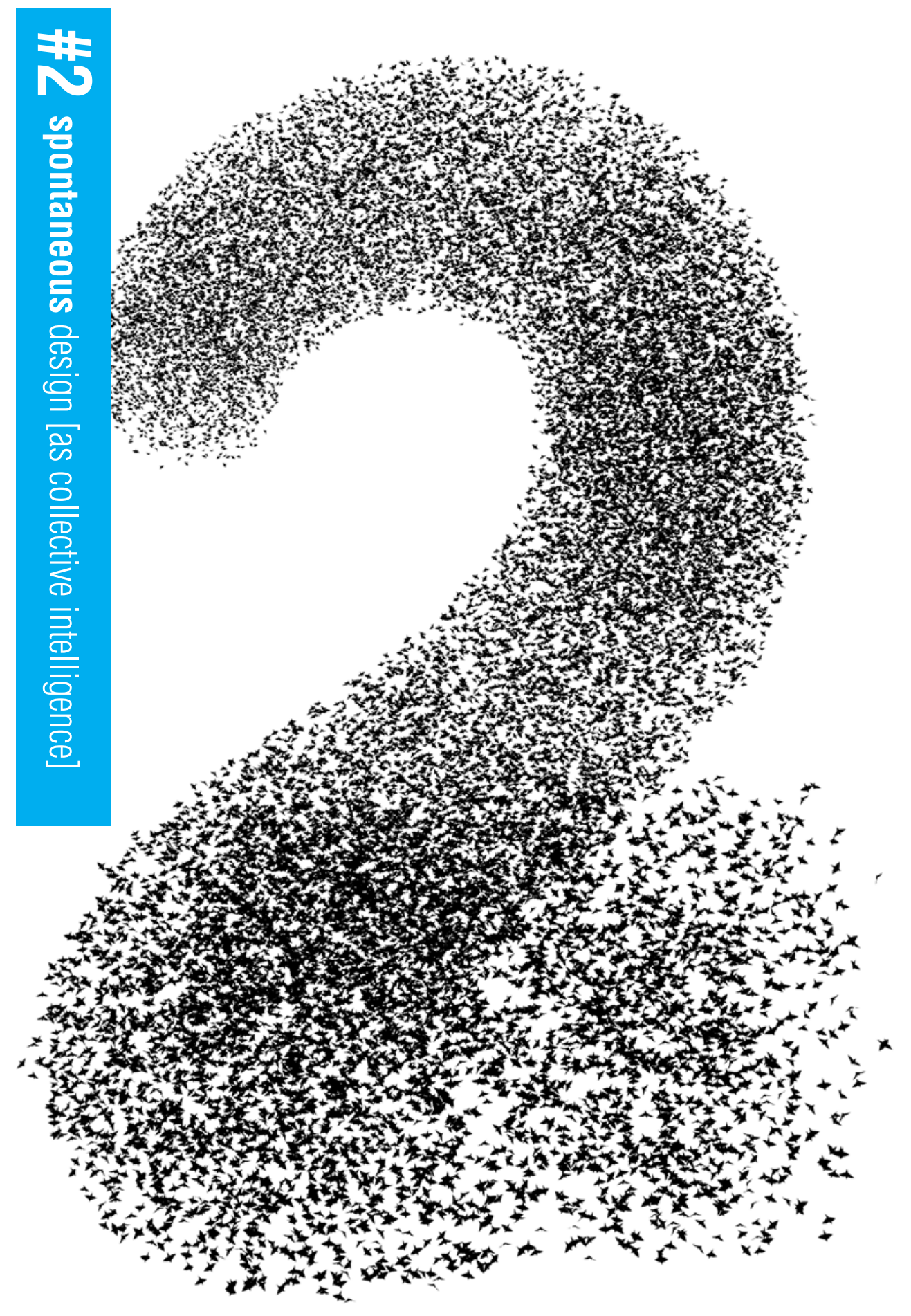

\section{DESIGN IN THE 'SMARTNESS OF THE ROOM'}

spontaneous design, design knowledge,

common ground, agents of change

How can Design renovate its skills and methods to not disappear (as knowledge) in the 'smartness of the room'?

It is not so simple to give a clear reply to these questions. What is possible to note, and maybe it is useful to understand, is that the phenomena of Design as Collective Intelligence cannot be considered a result but a tool that depends on the cultural, social, economic and political as well as technological context.

Therefore, it is more proper to talk about several Collective Intelligences and consequently several forms of Design.

Moreover, Design as Collective Intelligence cannot be translated as 'common thinking' or 'common behaviors'. It is not a question of mass. As tools, Design has to allow the individuals to express themselves creating, time by time, different communities, specific collectivities. 


\section{Abstract}

In his very recent book, Ezio Manzini (2015) focuses on the shift of Design role in the contemporary society where the technological and cultural changes - especially those due the computer science - are allowing everybody to be active part at the development processes. Considering 'Design as Collective Intelligence' means to attribute these skills not anymore at few experts people (designers) but to accept that everybody can have and use these skills and therefore to be designers. Disassembling and re-assembling the concepts inside the sentence 'Design as Collective Intelligence', the present paper try to open a possible interpretation of the new role of Design within what $D$. Weinberger (2012) calls the 'smartness of the room'.

Addressing the theme of 'Design as Collective Intelligence' is not simply to start a critic on one of the 'hot' issues of contemporaneity. It means to be in front three paradigmatic concepts that are undergoing sensitive transformations in the present-day.

These concepts are 'design', ‘intelligence' and 'collective'. The cultural and operational value of these three concepts is strong and full of consequences. In fact, if we consider them in the same phrase, they can describe a scenario fraught with meanings; but if we are taken them one by one, they are also in the core of distinct and significant debates from different disciplinary perspectives.

Therefore, in a sort of 'pun', it could be interesting to reflect on them in pairs and open, each time, a huge as well as different picture of meanings: 'intelligence and collective', 'collective and design', 'design and intelligence’.

\section{Intelligence and Collective}

The first of three pairs of words can be indeed considered a widely accepted and debated phenomenon, defined as 'Collective Intelligence'. Long before this expression was coined and recognized, some authors, dealing with applied sociology to political phenomena, had recognized in the dynamics of determination of the shared political thought, a form of 'collective intelligence'. Much later, with the advent of information technology, the definition of 'Collective Intelligence' has served to indicate that phenomenon of mass communication that today we can consider at its top.
"What is collective intelligence? It is a form of universally distributed intelligence, constantly enhanced, coordinated in real time, and resulting in the effective mobilization of skills... My initial premise is based on the notion of a universally distributed intelligence. No one knows everything, everyone knows something, all knowledge resides in humanity... New communications systems should provide members of a community with the means to coordinate their interactions within the same virtual universe of knowledge. This is not simply a matter of modeling the conventional physical environment, but of enabling members of delocalized communities to interact within a mobile landscape of signification... Before we can mobilize skills, we have to identify them. And to do so, we have to recognize them in all their diversity... The ideal of collective intelligence implies the technical, economic, legal, and human enhancement of a universally distributed intelligence that will unleash a positive dynamic of recognition and skills mobilization.” (Pierre Levy, 1994)

Today, the study of the phenomena of 'collective intelligence' is a discipline and applied research practiced, in particular, by the social and economic sciences. These studies try to understand, guide and prevent the decisions that large social groups can take to faced with political or cultural events or, more secularly, within the consumption choices.

And certainly, the factor that makes these studies so germinating is the capacity of these forms of 'intelligence' to produce benefits shared by a large group of people: that's why, in fact, these benefits were born and developed within the blocks. So they are not 'benefits' coming from top to down, but they are generated from bottom to up.

\section{Collective and Design}

Similarly, the 'lemma' that brings together the concepts of 'collective' and the concept of 'design' is referred to a recognized and practiced discipline for several decades. This is known as 'collaborative design' or 'participatory design' or, even, 'co-design'. In all cases, the emphasis is on the idea of designing together.

The idea on the base of 'participatory design' is quite straightforward: to design and to produce successful products (or services) we have to ask the people what they really want and what are their real needs (and desires). But according to the approach of 'participatory design', to ask is not sufficient, it needs to allow a relationship in between who is deputy to 
develop the product (or service) and the final users; or better, it needs to involve the final users in the development process.

Of course, this not means to transform everybody in a 'designer', but to enlarge the creative process to have more stimuli and more information. In fact, if according to the Collective Intelligence, any process of generation and transfer is peer-to-peer within the group, in the 'participatory design' process a 'hierarchical' condition is always accepted. In those case, some of the involved 'actors' - the designers and companies - 'listen' the others the users - to get to develop new concepts, practices, products.

This is because, whether to grant the user an influential role throughout the design process means to release a penetrating, expanded and destabilizing creative potential, there is ever-present a risk of generating an invisible but binding conformist vision based on 'groupthink'. (Whyte, 1952)

\section{Design and Intelligence}

In a way, this need to avoid the risk of loss of the design role has been the hidden reason that pushes someone to describe, to understand and (sometimes) to teach, to an even wider circle of the subject, what has been called 'design thinking'.

As we know, the 'design thinking' process is 'made' of overlapped spaces rather than of an ordinate sequence of steps. It starts from the understanding of the problem (inspiration), moves towards the proposals of possible solutions (ideation) to arrive at the application to a real context of the most logical solution (implementation).

In brief, we can agree that Design Thinking is a 'creative process' where the attention is focused on the understanding of the problem before the development of any possible the solution.

These means that 'design thinking' is a human-centred process not only because the expert (in our case, the designer) has to understand well the people needs but because the people are involved in the creative process According to Tim Brown (2009): "The job of the designer [...] is

'converting need into demand'. [...] is that we need to return human beings to the center of the story. We need to learn to put people first.”(p39).

Despite the 'Design Thinking' has come to the prominence thanks to the great and successful work of Ideo and its Ceo Tom Brown, this is not a new awareness. Already in 1969, Herbert A. Simon affirmed that the best: "Definition of design [is when] ... everyone is designing when to devise courses of action aimed at changing existing situations into preferred ones. The intellectual activity that produces material artifacts is no different fundamentally from the one that prescribes remedies for a sick patient or the one that devises a new sales plan for a company or a social welfare policy for a state.” (p. 130)

In the last years the cultural debate around 'design thinking' has grown exponentially with an huge number of different interpretations and applications.

For this discussion, it is interesting to note that Bruce Nussbaum (2011), observing how the diffusion of the 'design thinking' seems not to have produced the expected results, shift the attention on a particular feature of this creative process: that it can be 'collective' to be effective. He has renamed it as a 'Creative Intelligence’ stating that: "Design Thinking broke design out of its specialized, narrow, and limited base and connected it to more important issues and a wider universe of profit and non-profit organizations. I believe the concept of Creative Intelligence expands that social engagement even further."

Therefore, the 'design thinking', considered in this last 'version', brings us towards the last couple of words: 'design and intelligence'.

As far as we see, the three pairs of meanings obtained recombining the three original concepts - intelligence and collective, collective and design, design and intelligence - are strongly related representing the boundaries of the same scenario.

\section{Agents of Changing}

To better understand this relation of meanings, it could be useful to report one of the most interesting (and original) examples: the research presented in the U.S. Pavilion at the Biennale of Architecture of 2012 at Venice (Italy) Its meaningful title was 'Spontaneous Interventions: Design Actions for the Common Good, ${ }^{[1]}$.

The exhibition has been developed by the Institute for Urban Design and co-edited by Cathy Lang Ho, David Vander Leer and Ned Cramer. The exhibition has collected 124 projects developed by architects, designers, artist and 'simpler citizens'. The cultural thread that had linked these people is the convincement to be able to change in positive the (local) urban contexts, thanks to the direct participation of the final users.

The selection of these projects for the exhibition has been the result of a cal 
with more the 450 submissions from the United States. Each project has been analyzed according to different keywords (information, accessibility, community, economy, sustainability, recreation) while objective evaluations (in percentage) were associated to some distinct features, like the economic investment, the duration, the number of involved people.

The selected projects tell about an approach to the design of the living spaces (mental and physical one) and for the resolution of the social, economic and environmental issues, so simple and apparently effective to not need of any theoretical fundamental. Ideas with good intentions and great creative force that often bypass the 'official channels' to be developed and sometimes also going in contrast with the regulations.

These are ideas designed, manufactured and consumed from the bottom. Thanks to the typical determination of the ordinary people, which is convinced to be able to change their life, urban farms, social and shared public spaces, apps for the city way-finding, web platforms for urban planning based on crowd-sourcing born.

Why all these are projects 'not designed' from the top justifies the definition of 'spontaneous'. In fact, within the North American social and political tradition, the authors of these projects are social organizations, young designers, artists or architects distance from the cultural establishment, simpler citizens organized to work together only for a particular project, returning to be just users.

Within a sort of 'space' without higher rules, anyone can act at a 'personal level', searching small joint solutions at small shared problems, one by one. This way of doing reminds us the 'experimental utopie' of Lefebvre (1968) as well as the new agent defined by Toffler (1980) as fusion in between a producer and a consumer, the 'prosumer'.

The point is not only for each one to have the possibility to obtain the maximum 'customization' of the results, but rather to collectively personalize the process, maximizing the (few) available resources and if needed eluding the limits imposed by rules (market, social or economic rules).

The people who participate in these 'interventions' are not necessarily experts or professionally involved, they develop a new kind of capabilities finalized to change the present condition towards a more sustainable one: they are a sort of 'agents of changing' which act in a collective way.

Despite these 'spontaneous' interventions seem to be an instant and disjoint phenomenon, it is interesting to read the complexity of their cultural roots. In fact, they remind to those movements of the 60s and 70s expressed, in Europe, within the political and cultural actions (as the 'Situationists' and the 'Radical Design') and in the United States in the hippie counter-culture (Perniola, 1998).

As far as we can see, the 'interventions', promoted by these new 'agents of changing', put in act all the three pairs of concepts:

» they were based each time on a different 'collective intelligence', which opens a 'room to act' recognizing the particular problem, to find some possible solutions;

» they achieved a form of 'participatory design' asking to all members of the community to give their personal contribution for reach the results, or better the solution seems to be always conditioned by the involvement of the whole community;

» they used the approach of 'design thinking' to allow all members of the community to be part of the design process.

But in these interventions, we can find in this new process a bivalent risk. From one side, in fact, the full thrust on the 'participatory', risks triggering an autarchic mechanism in the creative process with a serious lack of innovation. This lack of innovation was happening to several social initiatives developed by citizens associations that not consider those political and economic systems that are on upstream of the social problem and that cannot have a resolution with isolated and particular projects. This, despite the good intentions, the human (and economic) resources involved, but due the self-referentiality of the outputs (product, service, human behaviors).

From the other side, even for another form of self-referentiality of the 'collective' process, the focus on the 'smartness' and efficiency of the single project diverts the attention of the real economic and productive sustainability of its process.

Above all, these 'interventions' represent an evolved stage of those previous phenomena of participatory actions: an evolution triggered, in particular, by the development of the information technologies and, in particular, of the web.

The web had changed the concept of community, which is not more referred to groups of people joined by physical proximity, but it is referred to homogeneous groups of people which share interests, cultures, activities, 
or, above all, knowledge. Today we don't just participate in a specific 'movement', to a defined group, to a codified ideology, we participate in a knowledge shared in the web community which is potentially unlimited.

The 'participation' generated by the web loses all kind of hierarchy because, at the contrary of the normal community, it is impossible in the virtual community to identify who takes the decisions (the decision-makers) and shares them with the others. The network generated in the web is horizontal, and it is hard to find the generative knot. Therefore, when before we note that the difference in between the 'collective intelligence' and the 'collaborative design' in the hierarchy of the roles within the community (or group), it seems that the web, fading the hierarchies, contributes to the convergence of this two (until now) separated phenomena.

As well described by D. Weinberger (2012), what is entirely changed in the participatory processes (especially in the participatory processes of knowledge) is the role of the (media) 'filters'. In fact, the old filters (the experts, which in our case are the designers) removed those data that the community did not take into consideration. While, the filters of the web potentially conserve everything: they just select, time by time, some contents without cancel the others but save them ready to be used in another context by another member of the community. A community where the smartest is not just one but the whole community that Weinberger calls the 'smart room'.

\section{Design as Tool}

But, in this horizontal process, where the new agents of changing act, which could be the role of the experts (of the physical filters)? How can Design renovates its skills and methods to not disappear (as knowledge) in the 'smartness of the room'?

It is not so simple to give a clear reply to these questions. What is possible to note, and maybe it is useful to understand, is that the phenomena of Design as Collective Intelligence cannot be considered a result but a tool that depends on the cultural, social, economic and political as well as technological context.

Therefore, it is more proper to talk about several Collective Intelligences and consequently several forms of Design.

Moreover, Design as Collective Intelligence cannot be translated as 'common thinking' or 'common behaviors'. It is not a question of mass.
As tools, it has to allow the individuals to express themselves creating, time by time, different communities, specific collectivities.

Design as Collective Intelligence has to accept the challenge to be a 'soft' push as well described by the economist R. Thaler and the jurist $\mathrm{C}$. Sunstein in their Book 'Nudge' (2008). They recognize, in contemporary society, the need for a push that has to be able of triggering practices of good citizenship, to help people to choose the best for themselves as well as for society.

Note

(1) http://www.spontaneousinterventions.org

\section{References}

Baudrillard, J. (1986) Amérique. FR: Grasset.

Brown, T. (2009). Change by Design: How Design Thinking Transforms Organizations and Inspires Innovation. U.S.: HarperCollins

Lefebvre, J. (1968). Le droit à la ville. FR: Éditions Anthropos.

Lévy, P. (1994). L’Intelligence collective. Pour une anthropologie du cyberespace. FR.: La Découverte

Manzini, E. (2015). Design, When Everybody Designs. U.S.: MIT Press

Nussbaum, B. (2011). Desi gn Thinking Is A Failed Experiment. So What's Next?. In FastCompany. April, 5 (retrieved in http://www.fastcodesign. com/1663558/design-thinking-is-a-failed-experiment-so-whats-next)

Perniola, M. (1998). I situazionisti, IT: Castelvecchi.

Simon, H. A. (1969). The Sciences of the Artificial. U.S.: MIT Press

Thaler, R.H. Sunstein, C.R. (2008). Nudge: Improving Decisions about Health, Wealth, and Happiness. U.S.: Yale University Press

Toffler, A. (1980). The Third Wave, U.S.: Bantam Books.

Weinberger, D. (2012). Too Big to Know: Rethinking Knowledge Now that the Facts aren't the Facts, Experts are Everywhere, and the Smartest Person in the Room is the Room. U.S.: Basic Books.

Whyte, W.H.J. (1952). Groupthink. in Fortune Magazine. March 